\title{
DIABETIC NEPHROPATHY; \\ CHANGES IN SERUM URIC ACID WITH ADVANCING STAGES
}

1. MBBS, M.Phil. Physiology, Ph.D. Scholar

Assistant Professor

Department of Physiology, Continental Medical College, Lahore

2. MBBS, FCPS (Physiology)

Assistant Professor

Department of Physiology, CMH Medical College, Multan

3. MBBS, M.Phil. Physiology

Assistant Professor

Department of Physiology, Continental Medical College, Lahore

Correspondence Address:

Dr. Muhammad Imran

Assistant Professor

Department of Physiology,

Continental Medical College, Lahore

70-Islam block, Azam Garden,

Multan Road, Lahore.

dr.imran.ap@gmail.com

Article received on:

19/10/2016

Accepted for publication:

03/01/2017

Received after proof reading:

06/04/2017

\section{Dr. Muhammad Imran', Dr. Muhammad Usman Bashir ${ }^{2}$, Dr. Ameena Nasir ${ }^{3}$}

ABSTRACT... Objectives: To compare serum uric acid levels in different stages of diabetic nephropathy. Study Design: Descriptive analytical study. Setting: University of Health Science Lahore. Period: February 2010 to January 2011. Subjects and methods: A sample size of 195 diabetic subjects. They were divided among normoalbuminuric, microalbuminuric and macroalbuminuric groups, according to their daily urinary albumin excretion rate (AER), with 65 patients in each group. Their glomerular filtration rate (GFR), daily AER and serum uric acid was evaluated by conducting tests on serum and urine samples. Statistics: KruskalWallis test and Mann-Whitney $\mathrm{U}$ test were used to observe differences of medians in different groups. $P$ value less than 0.05 was taken statistically significant. Results: There was majority of males in microalbuminuric and macroalbuminuric groups while females were more in number in normoalbuminuric group. Significant differences were found in serum urea concentration, serum creatinine concentration, serum uric acid concentration, glomerular filtration rate, urinary creatinine concentration, urine flow rate, daily albumin excretion rate and urinary albumin concentration among the three groups. Urinary creatinine concentration and glomerular filtration rate were in the highest ranges in normoalbuminuric group and in the lowest ranges in macroalbuminuric group. While rest of the parameters (ie. age, duration of diabetes, serum urea concentration, serum creatinine concentration, urine flow rate, daily AER, urinary albumin concentration and serum uric acid concentration) were in the lowest ranges in normoalbuminuric group and in the highest ranges in macroalbuminuric group. There was significant increase serum uric acid levels in advancing stages of diabetic nephropathy. $p<0.05$ was taken statistically significant. Conclusion: It is concluded that serum uric acid increases with the advancing stages of diabetic nephropathy. Progressive decline in glomerular filtration rate and gradual rise in serum creatinine level occurs throughout the course of diabetic nephropathy.

Key words: Serum uric acid, Diabetic nephropathy, Proteinuria, Glomerular filtration rate

Article Citation: Imran M, Bashir MU, Nasir A. Diabetic nephropathy; changes in serum uric acid with advancing stages. Professional Med J 2017;24(4):554-559.

DOI: $10.17957 / T P M J / 17.3681$
INTRODUCTION AND LITERATURE REVIEW

An important complication of diabetes mellitus is diabetic nephropathy (DN) and it is responsible for about $40 \%$ of new cases of ESRD in the United States. ${ }^{1}$ It is the leading cause of diabetes related morbidity and mortality. ${ }^{2} \mathrm{DN}$ is staged on the basis of degree of urinary albumin excretion rate
(AER) per day. According to American Diabetic Association (ADA), DN is classified in terms of microalbuminuria (urinary AER: $30-299 \mathrm{mg} /$ day); and macroalbuminuria (urinary AER: $\geq 300 \mathrm{mg} /$ day) ${ }^{3} \mathrm{~A}$ detailed classification has been proposed by Mogensen ${ }^{4}$ and is now generally accepted for both research and clinical purposes (Table-I).

$$
\begin{array}{l|l}
\text { Stage } 1 & \text { Glomerular hypertension and hypertorophy } \\
\hline \text { Stage } 2 & \text { Silent stage with normoalbuminuria (AER: }<30 \mathrm{mg} / 24 \text { hours) } \\
\hline \text { Stage } 3 & \text { Incipient diabetic nephropathy or microalbuminuria (AER: } 30-300 \mathrm{mg} / 24 \text { hours) } \\
\hline \text { Stage 4 } & \text { Overt diabetic nephropathy or macroalbuminuria (AER: }>300 \mathrm{mg} / 24 \text { hours } \\
\hline \text { Stage } 5 & \text { End stage renal disease }
\end{array}
$$

Table-I. Stages of diabetic nephropathy ${ }^{4}$ 
The exact pathogenesis of DN is complex and is not fully known. ${ }^{5}$ But like other microvascular complications, it is related to chronic hyperglycemia. The mechanisms by which chronic hyperglycemia leads to ESRD involve the effects of soluble factors, hemodynamic alterations in the renal microcirculation and structural changes in the glomerulus. ${ }^{2}$ Hyperglycemia leads to the activation of oxidative stress and increased production of reactive oxygen species. ${ }^{6}$

An important factor that is associated with kidney disease is serum uric acid. Hyperuricemia may be a marker of or by itself cause microvascular disease through activation of the renin angiotensin system (RAS) and inhibition of endothelial nitric oxide (NO). ${ }^{7}$ Serum uric acid in the high normal range is correlated with decreased renal function in patients with DM and normo or micro-albuminuria. ${ }^{8}$ Diabetic patients have altered endothelial function that may be associated with free radical production and is liable to xanthine oxidase inhibition with allopurinol therapy which also decreases serum uric acid levels. ${ }^{9}$ It is proposed that serum uric acid levels in the higher end of the normal range are independent predictor for overt DN. ${ }^{10}$ The mechanism causing hyperuricemia as a result of decreased renal clearance of uric acid can involve a reduced GFR or abnormal handling of uric acid by proximal tubules in kidneys. ${ }^{11}$ In type $2 \mathrm{DM}$, the compensatory hyperinsulinemia, secondary to insulin resistance, causes antiuricosuric effect on the kidney. ${ }^{12}$ Elevated serum uric acid may itself increase the risk for development of renal disease in normal as well as diabetic population and hyperuricemia is stronger predictor of renal failure than proteinuria. ${ }^{13}$ Serum uric acid can function as a proinflammatory molecule. ${ }^{14}$ As a result, cyclooxygenase-2, specific mitogenactivated protein kinases, inflammatory mediators (eg. C-reactive protein and monocyte chemo-attractant protein-1), and the RAS are upregulated, and endothelial NO production may be inhibited. ${ }^{15}$ Damage to vascular endothelium ${ }^{16}$ may be initiated in pre-glomerular vessels and result in injury to the renal interstitium. ${ }^{17}$ Whether the cause or the effect of renal function decline, hyperuricemia is invariably present in chronic renal disease. ${ }^{18}$ In our population this correlation has to be re-evaluated due to different pattern of genetic makeup and dietary habits, including low protein intake. Also hyperuricemia, if found to be correlated with advancing stages of DN, may warrant therapeutic interventions to minimize deleterious effects of uric acid on kidneys.

\section{STUDY SETTINGS, SUBJECTS AND SAMPLING} The study was a descriptive, analytical study, which was conducted in University of Health Sciences, Lahore. The study span was one year.

A population of 195 diabetic subjects was selected according to inclusion and exclusion criteria, and was divided into 3 groups, as follows:

- Group A: 65 macroalbuminuric patients

- Group B: 65 microalbuminuric patients

- Group C: 65 normoalbuminuric patients

Then convenient sampling was done among the registered cases of diabetes mellitus from tertiary care hospitals of Lahore.

The subjects selected were:

- Diagnosed patients of DM

- Both male and female patients irrespective of age

The subjects with following diseases/conditions were excluded:

- Gout

- Current use of diuretics or uricosuric drugs

- Serum creatinine $>2 \mathrm{mg} / \mathrm{dL}$

- Overt kidney disease, other than DN

- Urinary tract infection

\section{METHODOLOGY}

The patients were selected from the medical wards and diabetic clinics of the tertiary care hospitals of Lahore and medical record of every patient was assessed for concomitant medical condition (eg. gout) or any overt kidney disease other than DN. After taking written informed consent, the data of the subjects was collected and individuals were assessed by taking history and performing physical examination, using specially designed 
questionnaire. Blood and urine samples were taken. Blood samples were used to measure serum uric acid, urea and creatinine. Patient's urine was assessed for proteinuria on the bedside, with the help of Urinalysis Reagent Strips. Proteinuric state determined that the patient was having macroalbuminuria, while non-proteinuric state determined that the patient was either having microalbuminuria or normoalbuminuria. So for the quantitative and accurate determination of albumin levels in the urine, more sensitive technique of radioimmunoassay was utilised on 24 hour urine samples. GFR was calculated using the formula:

$\mathrm{GFR}=\mathrm{U} . \mathrm{V} / \mathrm{P}$

\section{STATISTICS}

After collecting the data, it was entered into and analyzed by SPSS (Statistical Package for Social Sciences) version 17.0. Kruskal-Wallis test and Mann-Whitney $U$ test were used to observe differences of medians in different groups. $p$ value less than 0.05 was taken statistically significant.

\section{RESULTS}

The three groups were compared for demographic data, serum uric acid levels and renal functions parameters. Following results were obtained:

The median serum uric acid concentration in the 3 groups showed significant difference from each other $(p<0.001)$. It was lowest in the normoalbuminuric group and highest in macroalbuminuric group (Table-III, Figure-1).

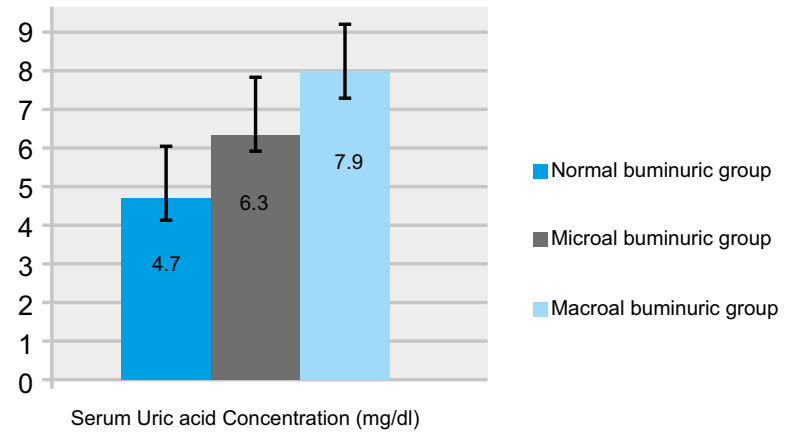

Figure-1. Comparison of serum uric acid concentration among normoalbuminuric, microalbuminuric and macroalbuminuric group. $p<0.001$

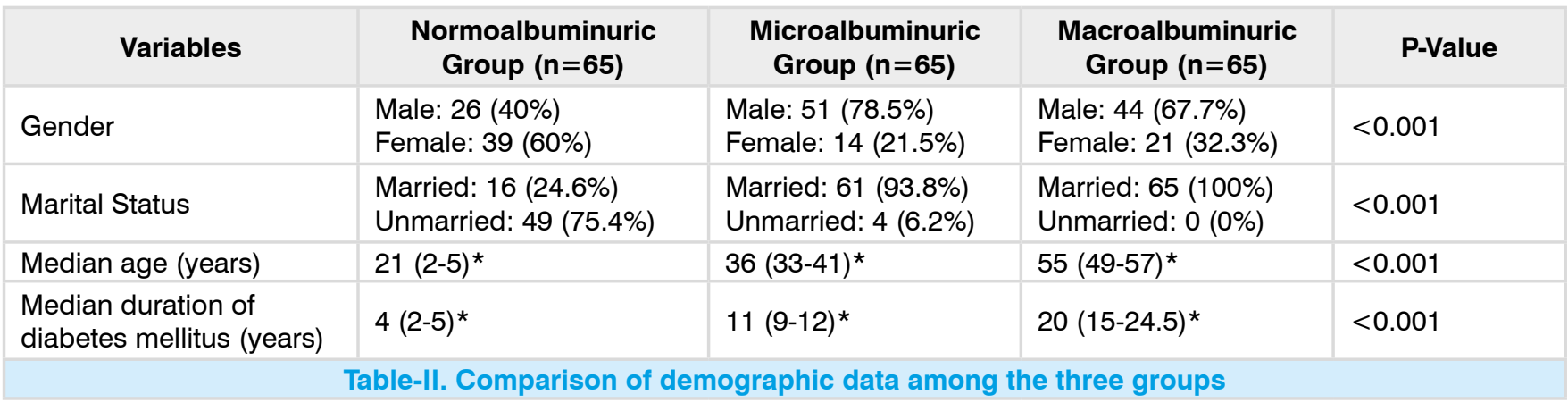

\begin{tabular}{|l|l|l|l|l|}
\hline \multicolumn{1}{|c|}{ Variables } & \multicolumn{1}{|c|}{$\begin{array}{c}\text { Normoalbuminuric } \\
\text { Group }(\mathbf{n = 6 5 )}\end{array}$} & $\begin{array}{c}\text { Microalbuminuric } \\
\text { Group }(\mathbf{n = 6 5})\end{array}$ & $\begin{array}{c}\text { Macroalbuminuric } \\
\text { Group (n=65) }\end{array}$ & \multicolumn{1}{|c|}{ P-Value } \\
\hline $\begin{array}{l}\text { Median serum uric acid } \\
\text { concentration (mg/dL) }\end{array}$ & $4.7(3.7-5.3)^{\star}$ & $6.3(5.9-7.15)^{\star}$ & $7.9(7.2-8.5)^{\star}$ & $<0.001$ \\
\hline $\begin{array}{l}\text { Median daily albumin } \\
\text { excretion rate }(\mathrm{mg} / \mathrm{day})\end{array}$ & $16(12-21)^{\star}$ & $163(113-232)^{\star}$ & $568(531-617)^{\star}$ & $<0.001$ \\
\hline $\begin{array}{l}\text { Median glomerular } \\
\text { filtration rate }(\mathrm{L} / \mathrm{day})\end{array}$ & $149.4(140.4-164.2)^{\star}$ & $115.2(105.4-130.6)^{\star}$ & $92.2(88.2-95.35)^{\star}$ & $<0.001$ \\
\hline $\begin{array}{l}\text { Median serum urea } \\
\text { concentration (mg/dL) }\end{array}$ & $37(28.5-46.5)^{\star}$ & $66(58-73)^{\star}$ & $101(87.5-150.5)^{\star}$ & $<0.001$ \\
\hline $\begin{array}{l}\text { Median serum creatinine } \\
\text { concentration (mg/dL) }\end{array}$ & $0.9(0.8-0.95)^{\star}$ & $1.1(1.1-1.2)^{\star}$ & $1.7(1.6-1.9)^{\star}$ & $<0.001$ \\
\hline
\end{tabular}

Table-III. Comparison of serum uric acid and renal parameters among the three groups 


\section{DISCUSSION}

Many important differences in parameters were seen among the three groups. Generally, it was the macroalbuminuric group that was the worst in renal function parameters. However the differences existed in every parameter of study. Although the number of females was greater in normoalbuminuric group, where they were constituting $3 / 5^{\text {th }}$ of the subjects, the males clearly outnumbered females in the other two groups. In microalbuminuric group, males were nearly $4 / 5^{\text {th }}$ and in macroalbuminuric group, they constituted slightly more than $2 / 3^{\text {rd }}$ of the subjects in the group. The higher percentage of males in the groups which were having advanced stage of DN may showed that the prevalence of DN may be greater in male individuals of the society, and therefore they presented more frequently in tertiary care hospitals and had more chances of being selected as study subjects. Hovind et al. worked on patients with DN and majority of the subjects in all three groups in their study were males, with $56 \%$ in normoalbuminuric, $67 \%$ in microalbuminuric and $70 \%$ in macroalbuminuric group. ${ }^{10}$

The marital status also showed a specific trend in our study. The married subjects in normoalbuminuric group were only about $1 / 4^{\text {th }}$ of the total diabetics in the group but they exceeded $90 \%$ of the cases in microalbuminuric group and there was no unmarried subject in macroalbuminuric group. This also signifies that the unmarried subjects were younger and had less advanced disease and vice versa. Similarly the median duration since the diagnosis of DM was less (only 4 years) in normoalbuminuric group as compared to microalbuminuric group (11 years) and macroalbuminuric group (20 years). The duration of DM was also related with the age of the subjects. The longer the subjects were diabetic, the more advance their stage of nephropathy was. In a study conducted by Rosolowsky et al, the duration of DM was significantly more in subjects with microalbuminuria, than those with normoalbuminuria. ${ }^{19}$ This is consistent with the results of present study, in which the duration of DM progressively increased with stage of DN.
The AER exhibited a wide range of values among the three groups. In normoalbuminuric group the mean value was $16.42 \pm 0.75 \mathrm{mg} /$ day, in microalbuminuric group it was $168.54 \pm 8.7 \mathrm{mg} /$ day and in macroalbuminuric group it was 569.31 $\pm 6.29 \mathrm{mg} /$ day. The three groups of study were based on the level of albuminuria. The daily AER significantly correlated with the renal function and there was significant difference of renal function status among the three groups. Rigalleau et al. worked on normoalbuminuric subjects who were having renal insufficiency. ${ }^{20}$

Serum uric acid was found to be significantly different among the groups. There was a gradual rise of serum uric acid levels among the groups and mean serum uric acid levels were $4.53 \pm 0.12$ (median: 4.7), $6.50 \pm 0.08$ (median: 6.3) and 7.77 \pm 0.12 (median: 7.9 ) $\mathrm{mg} / \mathrm{dL}$, in normoalbuminuric, microalbuminuric and macroalbuminuric groups respectively. This finding is consistent with the previous work done by Hovind et al., in which they described that serum uric acid levels, even in the high normal range, may cause microvascular disease and may predict the development of overt DN. ${ }^{10}$ Hovind et al. showed mean serum uric acid values of $3.49 \pm 0.96,3.51 \pm 0.93$ and $3.98 \pm 1.01$ $\mathrm{mg} / \mathrm{dL}$, in normoalbuminuric, microalbuminuric and macroalbuminuric groups respectively, with the results not statistically significant. ${ }^{10}$

In the study conducted by Rosolowsky et al., serum uric acid levels were significantly different in normoalbuminuric and microalbuminuric groups, with mean values of $4.2 \pm 1.0$ and 5.2 $\pm 1.5 \mathrm{mg} / \mathrm{dL}$ in these groups respectively. ${ }^{9}$ Safi et al. conducted a study in Khyber Medical College, and observed that serum uric acid levels were significantly higher in diabetic patients as compared to non-diabetic controls, with mean values being $6.07 \mathrm{mg} / \mathrm{dL}$ and $5.01 \mathrm{mg} / \mathrm{dL}$ in the above two groups. ${ }^{21}$ We also attempted to correlate serum uric acid levels of the subjects with the renal function parameters, as serum uric acid invariably increases with impairment in renal function. It was an unexpected result that serum uric acid was not correlated with renal function parameters in any of the groups. In our 
study, the results did not show any significant correlation of serum uric acid with GFR, serum urea or serum creatinine. In a study conducted by Nwankwo et al. in 2006, significant correlation was found between serum uric acid and the slope of the reciprocal of serum creatinine. ${ }^{22}$ Serum uric acid levels were expressed in $\mu \mathrm{mol} / \mathrm{L}$, with the conversion method being to divide the value (in $\mu \mathrm{mol} / \mathrm{L})$ by 60 to obtain results in $\mathrm{mg} / \mathrm{dL}$.

The renal function status was assessed by measuring GFR, serum urea and creatinine levels. The GFR significantly differed among the three groups which is consistent with the previous work. ${ }^{20}$ GFR was inversely correlated with the albuminuric state in the normoalbuminuric and macroalbuminuric groups. GFR depends on various factors: urine flow rate, daily water intake, dietary protein intake and even the environmental temperatures. These factors may be different in different countries, and even different regions in the same country. So although the normal range of GFR is taken to be $80-130 \mathrm{~mL} / \mathrm{min} / 1.73 \mathrm{~m}^{2},{ }^{23}$ the normal values must be described for every region and ethnic group of the world, specially for our country, in order to have a clear idea of the normal and abnormal values. With the advancing stage of DN, GFR decline occurs at the rate of 10 $\mathrm{mL} / \mathrm{min}$ per decade. ${ }^{23}$ That is the reason why ADA now recommends screening of chronic kidney disease (CKD) in diabetic patients, based both on daily AER and GFR. ${ }^{24}$

In this study, serum urea and creatinine were taken as supportive parameters of renal function status and gave expected results in relation to stages of DN. These parameters were significantly different among the three groups with the lowest values in normoalbuminuric group and highest values in the macroalbuminuric group. Serum urea and creatinine are routine markers for renal function decline and therefore have been incorporated in various equations of GFR calculation. ${ }^{25}$ Serum creatinine is also used for indirect assessment of GFR and has been used by various researchers for this purpose. Nwankwo et al. used the reciprocal of serum creatinine concentration as a means of GFR determination. ${ }^{22}$ The values of serum creatinine were given in $\mu \mathrm{mol} / \mathrm{L}$ in majority of the studies, with the conversion method being to divide the value of $\mu \mathrm{mol} / \mathrm{L}$ by 88.4 to obtain values in $\mathrm{mg} / \mathrm{dL}$. Also the creatinine clearance is used to roughly estimate GFR, because a small amount of it is secreted by the tubules, so that the amount of creatinine excreted slightly exceeds the amount filtered. On the other hand, there is normally a slight error in measuring plasma creatinine, that results in an overestimation of the plasma creatinine concentration. These two errors almost cancel each other, so that the creatinine clearance provides a reasonable estimate of GFR. ${ }^{26}$

\section{CONCLUSION}

It is concluded that serum uric acid increases with the advancing stages of diabetic nephropathy and progressive decline in glomerular filtration rate and gradual rise in serum creatinine level occurs throughout the course of diabetic nephropathy.

Copyright (C) 03 Jan, 2017.

\section{REFERENCES}

1. American Diabetic Association: Diagnosis and classification of diabetes mellitus (Position Statement). Diabetes Care 2004; 27 (1): S5-10.

2. Powers AC: Diabetes mellitus. In: Harrison's Principles of Internal Medicine, $17^{\text {th }}$ Ed., Boston, Editors: Kasper DL, Braunwald E, Fauci AS, Hauser SL, Longo DL, Jameson JL, Loscalzo J. McGraw-Hill 2008: 2275-304.

3. American Diabetic Association: Nephropathy in diabetes (Position Statement). Diabetes Care 2004; 27 (1): S79-83.

4. Mogensen CE: Definition of diabetic renal disease in insulin dependent diabetes mellitus based on renal function tests. In: The kidney and hypertension in diabetes mellitus, $3^{\text {rd }}$ ed. Boston, edited by Mogensen CE, Kluwer academic publishers 1997;11-22.

5. Parving $\mathrm{HH}$, Mauer M, Ritz E: Diabetic nephropathy. In: The Kidney. 7th ed. Brenner BM, Saunders WB 2004: 1777-818.

6. Ruggenenti P, Remuzzi G: Nephropathy of type-2 diabetes mellitus. J Am Soc Nephrol 1998; 9:2157-69.

7. Mene P, Punzo G: Uric acid: bystander or culprit in hypertension and progressive renal disease? J Hypertens 2008; 26:2085-92. 
8. Rosolowsky ET, Ficociello LH, Maselli NJ, Niewczas MA, Binns $A L$, Roshan $B$ et al: High-normal serum uric acid is associated with impaired glomerular filtration rate in non-proteinuric patients with type 1 diabetes. Clin J Am Soc Nephrol 2008; 3:706-13.

9. Butler R, Morris AD, Belch JJF, Hill A, Struthers AD: Allopurinol Normalizes Endothelial Dysfunction in Type 2 diabetes with Mild Hypertension. Hypertension 2000; 35:746-51.

10. Hovind P, Rossing P, Tarnow L, Johnson RJ, Parving $\mathrm{HH}$ : Serum uric acid as a predictor for development of diabetic nephropathy in type 1 diabetes - an inception cohort study. Diabetes Online (May 1) 2009.

11. Perez-Ruiz F, Calabozo M, Erauskin GG, Ruibal A, Herrero-Beites AM: Renal underexcretion of uric acid is present in patients with apparent high urinary uric acid output. Arthritis Rheum 2002; 47: 610-3.

12. Moriwaki $\mathrm{Y}$, Yamamoto $\mathrm{T}$, Takahashi S, Suda M, Higashino K: Effect of glucose infusion on the renal transport of purine bases and oxypurinol. Nephron 1995; 69(4):424-7.

13. Iseki K, Oshiro S, Tozawa M, Iseki C, Ikemiya Y, Takishita $S$ : Significance of hyperuricemia on the early detection of renal failure in a cohort of screened subjects. Hypertens Res 2001; 24: 691-7.

14. Johnson RJ, Kang DH, Feig D, Kivlighn S, Kanellis J, Watanabe $S$ et al.: Is there a pathogenetic role for uric acid in hypertension and cardiovascular and renal disease? Hypertension 2003; 41: 1183-90.

15. Coutinho Tde A, Turner ST, Peyser PA, Bielak LF, Sheedy PF 2nd, Kullo IJ: Associations of serum uric acid with markers of inflammation, metabolic syndrome, and subclinical coronary atherosclerosis. Am J Hypertens 2007; 20(1): 83-9.

16. Hayden MR and Tyagi SC: Uric acid: A new look at an old risk marker for cardiovascular disease, metabolic syndrome, and type 2 diabetes mellitus-the urate redox shuttle. Nutr Metab 2004, 1, 10.
17. Johnson RJ, Herrera-Acosta J, Schreiner GF and Rodriguez-Iturbe B: Subtle acquired renal injury as a mechanism of salt-sensitive hypertension. $\mathrm{N}$ Engl $\mathrm{J}$ Med 2002, 346, 913-23.

18. Wortmann RL: Disorders of purine and pyrimidine metabolism. In: Harrison's Principles of Internal Medicine, 16 ${ }^{\text {th }}$ Ed., Boston, Editors: Kasper DL, Braunwald E, Fauci AS, Hauser SL, Longo DL, Jameson JL.McGraw-Hill; 2005:2308-13.

19. Rosolowsky ET, Niewczas MA, Ficociello LH, Perkins $\mathrm{BA}$, Warram JH, Krolewski AS: Between hyperfiltration and impairment: Demystifying early renal functional changes in diabetic nephropathy. Diabetes Res clin pract. 2008; 82(1) S46-53.

20. Rigalleau et al: Normoalbuminuric renal-insufficient diabetic patients. Diabetes Care 2007, 30, 2034-39.

21. Safi AJ: Association of serum uric acid with type 2 diabetes mellitus. J Postgrad Med Inst 2004, 18(1), 5963.

22. Nwankwo EA, Wudiri WW, Gadzama AA: Serum uric acid correlates with the prog-ression of nephropathy in patients with diabetes mellitus. Pak J Med Sci 2006; 22: 391-5.

23. Granerus G, Aurell M: Reference values for $51 \mathrm{Cr}$ EDTA clearance as a measure of glomerular filtration rate. Scand J Clin Lab Invest 1981; 41:611-6.

24. Kramer $\mathrm{H}$, Molitch $\mathrm{ME}$ : Screening for kidney disease in adults with diabetes. Diabetes Care 2005; 28: 18136.

25. Bostom et al: Predictive performance of renal function equations for patients with chronic kidney disease and normal serum creatinine levels. J Am Soc Nephrol 2002, 13:2140-44.

26. Hall JE: Urine formation by the kidneys: II. Tubular reabsorption and secretion. In Guyton and Hall Textbook of Medical Physiology, $12^{\text {th }}$ ed., USA, Philadelphia, Elsevier Inc. 2011: 323-43.

\section{AUTHORSHIP AND CONTRIBUTION DECLARATION}

\begin{tabular}{|c|l|l|}
\hline Sr. \# & \multicolumn{1}{|c|}{ Author-s Full Name } & \multicolumn{1}{|c|}{ Contribution to the paper } \\
\hline 1 & Dr. Muhammad Imran & $\begin{array}{l}\text { Conducted the main research and } \\
\text { edited the article as a whole. }\end{array}$ \\
\hline 2 & Dr. M. Usman Bashir & $\begin{array}{l}\text { Provided help in statistical } \\
\text { analysis and discussion writing } \\
\text { Performed tests and formalated } \\
\text { results }\end{array}$ \\
\hline
\end{tabular}

